\title{
Adsorption of Fluorescent Brighteners by Regenerating Protoplasts of Aspergillus nidulans
}

\author{
By J. F. PEBERDY AND C. E. BUCKLEY \\ Department of Botany, University of Nottingham, University Park, Nottingham, $N_{7}{ }_{2} R D$
}

(Received I2 April I972; revised I6 August 1972)

\section{SUMMAR Y}

A possible method using fluorescent brighteners for estimating the rate of wall accumulation by regenerating protoplasts is described. The relationship between the amount of wall and brightener adsorption was linear. Phases of slow and rapid brightener adsorption, thought to be correlated with chain and hypha formation respectively, were found during regeneration. The length of the slow phase varied according to the composition of the regeneration medium.

\section{INTRODUCTION}

Optical brighteners, used in paper and textile treatment and incorporated into detergents, are absorbed by growing fungi (Darken, I962). These compounds are highly fluorescent when excited by u.v. light and are stable and non-toxic to micro-organisms at low concentrations. They have been used as vital and direct stains for bacteria, slime moulds and fungi (Harrington \& Roper, 1968; Paton \& Jones, 197I ; Preece, 197I). Brighteners have also been used to demonstrate the absence of wall material and the development of new wall materials during regeneration in both fungal and higher plant protoplasts (Nagata \& Takebe, I970; Peberdy \& Gibson, I97I ; Gull, Moore \& Trinci, 1972).

Previous studies on regeneration of protoplasts from moulds have been mainly of a morphological nature (Emerson \& Emerson, 1959; Elorza, Arst, Cove \& Scazzocchio, I969; Peberdy \& Gibson, I97I), but current investigations in this laboratory have necessitated the development of a technique whereby regeneration can be estimated quantitatively. Bachmann \& Bonner (1958) attempted to estimate the process in Neurospora crassa by plating out on agar media, but because of clumping of protoplasts it was impossible to obtain satisfactory results. More recently Garciá-Acha, López-Belmonte \& Villanueva (I966) using semisolid regeneration media were able to quantify regeneration of Fusarium culmorum protoplasts by microscopic counts. However, this method has proved to be inaccurate in our experiments in which high concentrations of protoplasts were used and clumping of the regenerated structures occurred.

The specificity of fluorescent brighteners for wall components and the uptake of these compounds by the regenerating walls of protoplasts indicated a possible alternative procedure, the details of which are reported here.

\section{METHODS}

Organisms. Aspergillus nidulans (Eidam) Winter wild-type strain was grown on malt extract agar (Oxoid) for both maintenance and for the preparation of conidial suspensions. Streptomyces venezulae RA was maintained on Kuster \& Williams's (1964) medium. 


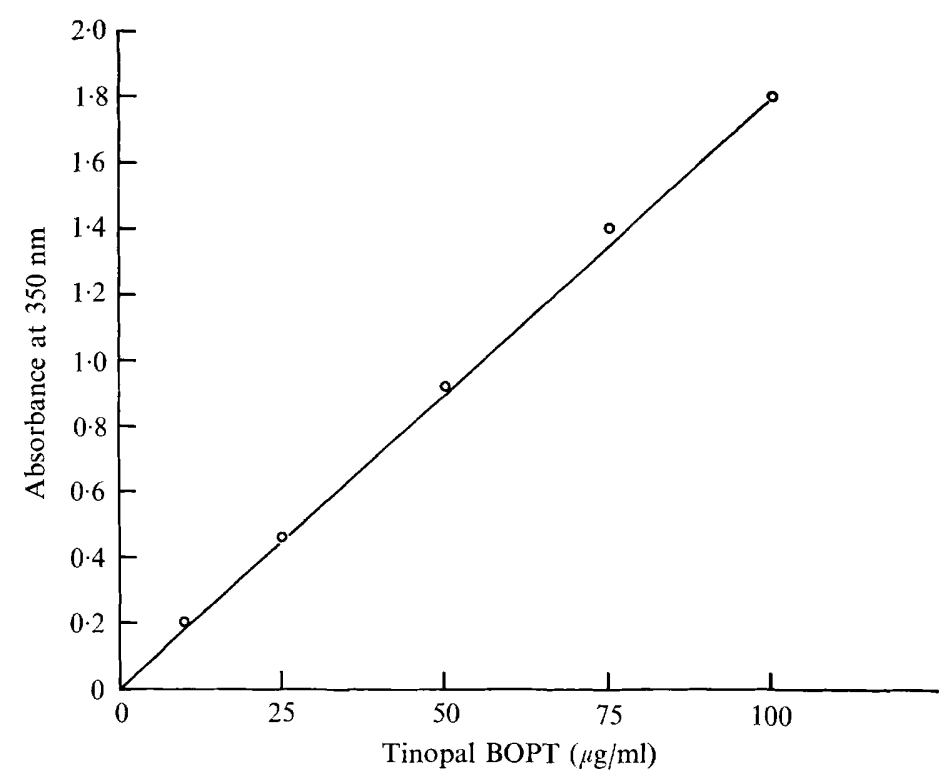

Fig. I. Absorbance of Tinopal BOPT solutions at $350 \mathrm{~nm}$. Measurements made in I cm cells.

Preparation of isolated walls. Walls were prepared from $48 \mathrm{~h}$ mycelium of Aspergillus nidulans grown on the medium described below, by using the methods of Peberdy (I97I).

Preparation of the lytic enzyme. The lytic enzyme, containing chitinase and $\beta, \mathrm{I}-3$ glucanase as its main components, was prepared from the Streptomyces grown for 7 days on a salts medium based on that used by Bull (1970) and containing chitin, $0.25 \%$ (Sigma, London), laminarin, $0.25 \%$ (Koch-Light, Colnbrook, Buckinghamshire), and yeast extract, $0 . \mathrm{I} \%$. Batch cultures, 7.51 in a Io 1 fermenter vessel (L. H. Engineering Co. Ltd, Stoke Poges, Buckinghamshire), were stirred at $1000 \mathrm{rev} . / \mathrm{min}$ and aerated by a sparger located directly beneath the impeller with an air flow of $7.51 / \mathrm{min}$. Further details on the preparation of lytic enzyme have been described by Peberdy \& Gibson (1971).

Preparation of protoplasts. Protoplasts were obtained from $48 \mathrm{~h}$ cultures of Aspergillus nidulans grown in AM medium (Peberdy \& Gibson, 1971). One 1 bottles containing $750 \mathrm{ml}$ medium were inoculated with $10^{7}$ spores and aerated at $2.5 \mathrm{l} / \mathrm{min}$. The mycelium was harvested by filtration, washed and finally resuspended in $0.2 \mathrm{M}$-phosphate buffer, $\mathrm{pH} 6.4$, containing $0.8 \mathrm{M}-\mathrm{NH}_{4} \mathrm{Cl}$, I g mycelium (fresh wt) $/ \mathrm{ml}$ buffer. Equal volumes of mycelium suspension and lytic enzyme were incubated at $28^{\circ} \mathrm{C}$, with shaking, for $2 \mathrm{~h}$. Protoplasts were isolated and prepared for regeneration as described previously (Peberdy \& Gibson, 1971).

Regeneration of protoplasts. Regeneration media were based on AM medium supplemented with $0.4 \mathrm{M}-\mathrm{NH}_{4} \mathrm{Cl}$, as osmotic stabilizer, and either glucose (I00 g/l) and yeast extract $(2.5 \mathrm{~g} / \mathrm{l})$ or glucose ( $100 \mathrm{~g} / \mathrm{l})$ and $N$-acetylglucosamine (NAG) $(2.5 \mathrm{~g} / \mathrm{l})$ or glucose alone $(100 \mathrm{~g} / \mathrm{l})$. Protoplast suspensions $\left(10^{6} / \mathrm{ml}\right)$ were incubated in the regeneration media at $25^{\circ} \mathrm{C}$. Control flasks, to account for spores that may have been present, were prepared by lysing the protoplasts at the start of incubation. Samples ( $\mathrm{I} \mathrm{ml}$ ) were removed from the suspensions at intervals and centrifuged at $500 \mathrm{~g}$ for $10 \mathrm{~min}$. The protoplasts were resuspended in buffer containing stabilizer and homogenized in a Elvehjem homogenizer. The 
Table I. Stability of Tinopal BOPT solution ( $100 \mu \mathrm{g} / \mathrm{ml}$ ) stored in clear glass and actinic glass exposed to daylight

$\begin{array}{ccc}\begin{array}{c}\text { Exposure time } \\ \text { (min) }\end{array} & \overbrace{\text { Clear glass }}^{\text {Absorbance at } 350 \mathrm{~nm}} \\ 0 & \mathrm{I} \cdot 72 & \mathrm{I} \cdot 72 \\ \mathrm{O} & \mathrm{I} \cdot 37 & - \\ 2 & \mathrm{I} \cdot 04 & - \\ 3 & 0 \cdot 80 & - \\ 4 & 0 \cdot 70 & \mathrm{I} \cdot 73 \\ 6 & 0.42 & - \\ 8 & 0.39 & \mathrm{I} \cdot 72 \\ \mathrm{IO} & 0.38 & \mathrm{I} \cdot 72 \\ \mathrm{I5} & 0.34 & \mathrm{I} \cdot 72 \\ 20 & 0.34 & \mathrm{I} \cdot 72 \\ 30 & - & \mathrm{I} \cdot 73 \\ 40 & - & \mathrm{I} \cdot 72 \\ 60 & - & \mathrm{I} \cdot 72\end{array}$

suspension was again centrifuged and the sediment washed twice in distilled water before finally resuspending in the fluorescent brightener solutions.

Adsorption of fluorescent brighteners. Fluolite HSP and XNR were kindly supplied by I.C.I. Ltd, Manchester, Photine LV by Hickson \& Welch Ltd, Castleford, Yorkshire, and Tinopal BOPT and 4 BMT by Ciba-Geigy (U.K.) Ltd, Manchester. Aqueous solutions ( 100 and $500 \mu \mathrm{g} / \mathrm{ml}$ ) were prepared and stored in dark glass bottles in the dark. A standard curve in the range 10 to $100 \mu \mathrm{g} / \mathrm{ml}$ is given in Fig. I. Samples (I ml) of isolated wall suspensions $(0 \cdot 2$ to $\mathrm{I} \mathrm{mg}$ dry $\mathrm{wt} / \mathrm{ml})$ were centrifuged and resuspended in $5 \mathrm{ml}$ of the brightener solutions for $5 \mathrm{~min}$ in the dark, by which time maximum uptake had occurred, and then centrifuged. The amount of brightener removed by the walls was determined by measuring the absorbance of the supernatant at $350 \mathrm{~nm}$ by means of a Unicam SP 1800 Spectrophotometer. Brightener adsorption by walls of regenerating protoplasts and control suspensions was determined in a similar manner. Three replicates of the washed sediments after homogenization were suspended in $5 \mathrm{ml}$ brightener solution and the removal of brightener estimated.

Stability of the brightener solutions was checked periodically by means of absorbance measurements on standard solutions containing $100 \mu \mathrm{g} / \mathrm{ml}$ of brightener. The stability of Tinopal BOPT solutions in clear glass and actinic glass containers is shown in Table I. Photine LV was known to undergo isomerization from trans to cis forms when exposed to light (D. Barton, personal communication) and the other compounds were assumed to behave similarly.

U.v. microscopy. Regenerating protoplasts were suspended in $0.1 \%$ brightener solutions containing $0.4 \mathrm{M}-\mathrm{NH}_{4} \mathrm{Cl}$ and left for $5 \mathrm{~min}$. The suspension was centrifuged, the protoplasts washed and resuspended in $0.4 \mathrm{M}-\mathrm{NH}_{4} \mathrm{Cl}$ and examined in a Leitz Ortholux microscope with a $2 \mathrm{~mm}$ red suppression and filter u.v. $2+\mathrm{I} \mathrm{mm}$ transmission filter. Mycelium and germinating spores were treated with $0.1 \%$ brightener solution and finally resuspended in water. Photographs were taken on Ilford $\mathrm{HP}_{4}$ film and developed in ID I (Ilford) for 6 min at $20{ }^{\circ} \mathrm{C}$. 

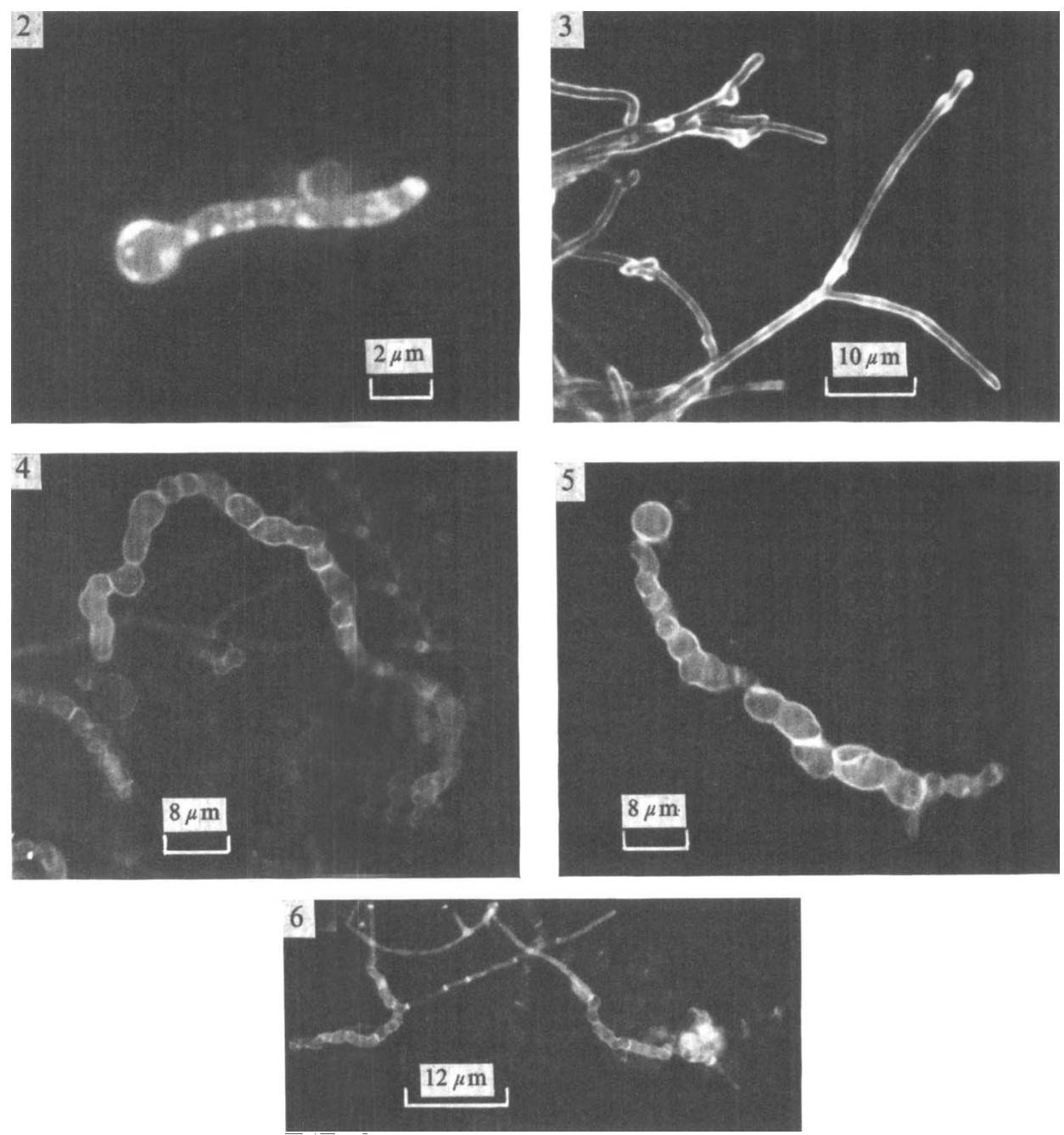

Fig. 2-6. All preparations were stained with Tinopal BOPT.

Fig. 2. Germinating conidium of Aspergillus nidulans. The margin of the spore and germ tube fluoresce and areas of intense fluorescence can be seen at the extreme tip and irregularly over the germ tube and spore.

Fig. 3. Mycelium of $A$. nidulans. The walls fluoresce uniformly with more intense fluorescence at the tips.

Fig. 4. Regenerating protplast of $A$. nidulans in glucose medium after $36 \mathrm{~h}$.

Fig. 5. Regenerating protoplast of $A$. nidulans in glucose medium after $36 \mathrm{~h}$ showing the initial stage of hypha formation.

Fig. 6. Regenerating protoplast of $A$. nidulans after $36 \mathrm{~h}$ in glucose+NAG medium. Hyphal growth is well established. Distinct septa are visible in the hypha arising from an intermediary cell of the chain. 


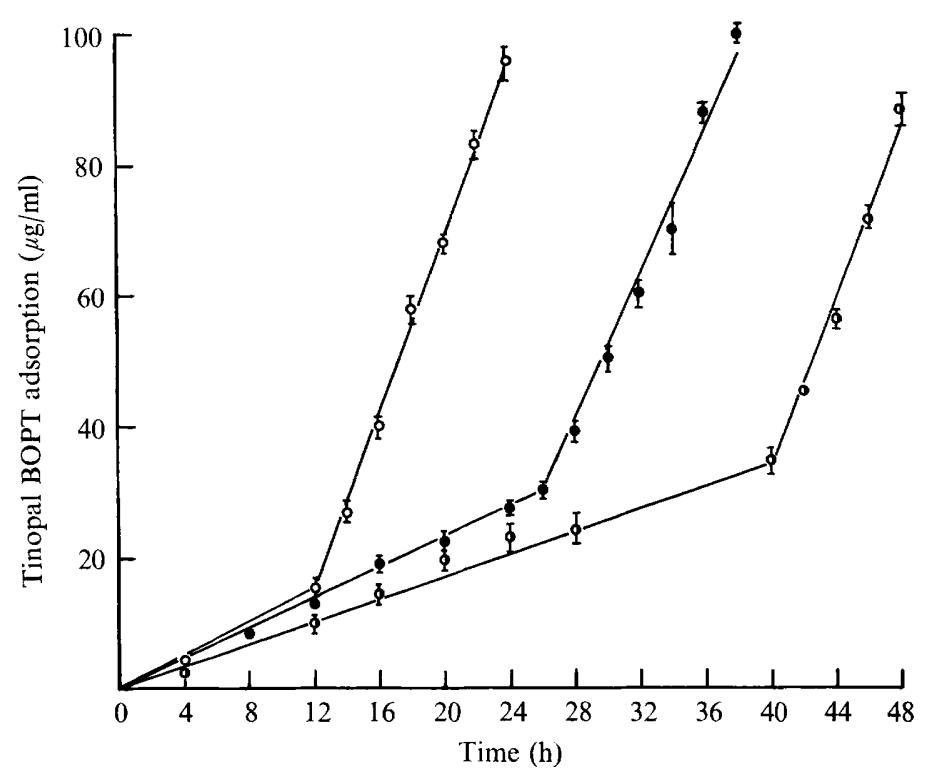

Fig. 7. Adsorption of Tinopal BOPT by regenerating protoplasts of Aspergillus nidulans. Protoplasts were sampled from three regeneration media $(--\infty-, 10 \%$ glucose; - $-\longrightarrow, 10 \%$ glucose $+0.25 \% \mathrm{NAG} ;-\mathrm{O}-\mathrm{O}-, 10 \%$ glucose $+0.25 \%$ yeast extract $)$. After homogenization the debris was suspended in brightener solution for $5 \mathrm{~min}$. The suspension was centrifuged and residual brightener concentrations in the supernatant determined.

Table 2. Adsorption of fluorescent brighteners by washed walls of Aspergillus nidulans

Known weights of isolated walls were suspended in $5 \mathrm{ml}$ of brightener solution for $5 \mathrm{~min}$. The suspension was centrifuged and the amount of brightener removed was determined by measuring the absorbance of the supernatant at $350 \mathrm{~nm}$.

\begin{tabular}{|c|c|c|c|c|c|c|}
\hline \multirow[b]{2}{*}{$\begin{array}{l}\text { Walls } \\
\text { (mg } \\
\text { dry wt) }\end{array}$} & \multicolumn{2}{|c|}{ Fluolite XNR } & \multicolumn{2}{|c|}{ Photine LV } & \multicolumn{2}{|c|}{ Tinopal BOPT } \\
\hline & $\begin{array}{l}\text { Brightener } \\
\text { removed } \\
(\mu \mathrm{g} / \mathrm{ml})\end{array}$ & $\begin{array}{l}\text { Brightener } \\
\text { adsorbed } \\
\text { ( } \mu \mathrm{g} / \mathrm{mg} \\
\text { dry walls) }\end{array}$ & $\begin{array}{c}\text { Brightener } \\
\text { removed } \\
(\mu \mathrm{g} / \mathrm{ml})\end{array}$ & $\begin{array}{l}\text { Brightener } \\
\text { adsorbed } \\
(\mu \mathrm{g} / \mathrm{mg} \\
\text { dry walls })\end{array}$ & $\begin{array}{c}\text { Brightener } \\
\text { removed } \\
(\mu \mathrm{g} / \mathrm{ml})\end{array}$ & $\begin{array}{c}\text { Brightener } \\
\text { adsorbed } \\
(\mu \mathrm{g} / \mathrm{mg} \\
\text { dry walls) }\end{array}$ \\
\hline 0.2 & $4 \cdot 2$ & $21 \cdot 0$ & $4 \cdot 6$ & $23 \cdot 0$ & 4.2 & $2 \mathrm{I} \cdot \mathrm{O}$ \\
\hline 0.4 & $8 \cdot 5$ & $22 \cdot 0$ & $9 \cdot 2$ & $23 \cdot 0$ & $8 \cdot 0$ & $20 \cdot 0$ \\
\hline 0.5 & 10.0 & 20.0 & $11 \cdot 4$ & $22 \cdot 8$ & $9 \cdot 8$ & 19.6 \\
\hline 0.6 & $12 \cdot 9$ & $21 \cdot 5$ & $13 \cdot 4$ & $22 \cdot 3$ & $12 \cdot 5$ & $20 \cdot 8$ \\
\hline 0.8 & $15 \% 9$ & 19.9 & $18 \cdot 9$ & $23 \cdot 5$ & $15 \cdot 6$ & $19 \cdot 5$ \\
\hline$I \cdot O$ & 19.8 & 19.8 & $22 \cdot 2$ & $22 \cdot 2$ & $20 \cdot 0$ & $20 \cdot 0$ \\
\hline
\end{tabular}

\section{RESULTS}

Microscopic observations of germinating spores, mycelium and regenerating protoplasts after treatment with fluorescent brighteners

The fluorescence exhibited by germinating spores is shown in Fig. 2. The tip of the germ tube stained very intensely and behind the apex localized areas of high fluorescence were visible as well as the outline of the spore wall and the germ-tube wall. Established mycelium tended to show more generalized fluorescence with uniformly stained walls and septa 
Table 3. Chain length of regenerating protoplasts of Aspergillus nidulans on different media

\begin{tabular}{lc}
\multicolumn{1}{c}{ Medium } & Chain length $(\mu \mathrm{m})^{*}$ \\
I0 $\%$ glucose & $47 \cdot 9 \pm \mathrm{I} \cdot 06^{\dagger}$ \\
I0 $\%$ glucose $+0.25 \%$ NAG & $30 \cdot 2 \pm 0.85$ \\
I0 $\%$ glucose $+0.25 \%$ yeast extract & $2 \mathrm{I} \cdot 7 \pm 0.69$
\end{tabular}

* Measurements made at $40 \mathrm{~h}$ for glucose medium, $26 \mathrm{~h}$ for glucose- $N$-acetylglucosamine medium and $\mathrm{I} 2 \mathrm{~h}$ for glucose-yeast extract medium.

$\dagger$ Mean values of 300 samples with standard error of mean. These values are significantly different on the basis of the $f$ test (Bailey, 1959).

(Fig. 3), but in some preparations hyphae with localized areas of intense staining were also seen.

The adsorption and fluorescence of regenerating protoplasts demonstrated the presence of wall material laid down during the formation of the chains. In some instances the intensity of the fluorescence increased as the chain lengthened and the terminal cell stained most strongly. Typical chain structures are shown in Fig. 4 and 5; the yeast-like cells separated by septa and the spherical terminal cell are clearly marked by the newly deposited wall. Hyphae with very distinct septa were found to develop from cells of the chain as well as from the terminal cell (Fig. 6), but the intensity of fluorescence of the hyphae was not as great as that of the chains of cells.

\section{Estimation of brightener adsorption by isolated walls and walls of regenerating protoplasts}

Fluolite HSP and Tinopal ${ }_{4}$ BMT proved to be unsuitable because of their insolubility at the concentrations used. Removal of the other three brighteners from solution by isolated walls is shown in Table 2 . The amount of brightener adsorbed by increasing concentrations of walls was reasonably constant for the different brighteners, as was the amount removed per unit weight of walls.

The adsorption of Tinopal BOPT by the newly formed walls of regenerating protoplasts, in three different media, is shown in Fig. 7. Two distinct phases were found, an initial phase when the amount of brightener adsorbed increased slowly followed, at varying time intervals, by a second phase of more rapid adsorption. Identical patterns of adsorption were obtained from Fluolite XNR and Photine LV.

\section{Chain length of regenerating protoplasts}

The length of the regenerating chains on the three media was determined at the time of transition between the two phases of brightener adsorption. The results (Table 3 ) show a significant difference in size.

\section{DISCUSSION}

Previous observations on the morphology of regenerating protoplasts from Aspergillus nidulans hyphae (Peberdy \& Gibson, I97I) have been confirmed and extended by the use of fluorescence microscopy and optical brighteners. The specificity of the brighteners for $\beta$-linked carbohydrate polymers (Maeda \& Ishida, 1967) provides a useful basis for demonstrating the presence of wall in regenerating protoplasts. Differences in intensity of fluorescence at germ-tube tips, the localized areas of hyphae and the older cells of the regenerating chains, may have reflected chemical differences in the walls at these regions, i.e. higher proportions of $\beta$-linked polymers, or differences in thickness of the wall or both. 
The method described to estimate formation of wall material by protoplasts was based on the u.v. absorbance properties, and the adsorbance by isolated walls, of the fluorescent brighteners. A lack of interference by intracellular carbohydrates was confirmed in two ways. Non-regenerating protoplasts, after homogenization, did not remove brightener from solution and more recently it was found that brightener adsorption was the same for regenerated protoplasts both before and after homogenization (C. E. Buckley, unpublished).

The two phases of brightener adsorption observed during regeneration may correlate with the morphological changes described previously (Peberdy \& Gibson, 197I). The initial phase would correspond to the formation and extension of the chains of yeast-like cells by the protoplasts and the second appears to relate to the formation and growth of hyphae from the majority of the regenerating structures. The duration of the first phase of adsorption was the main difference between the media. With glucose as the sole carbon source the transition point between the two phases occurred much later than on media supplemented with NAG and with yeast extract. The latter supported the most rapid regeneration in terms of duration of the first phase. Measurements of length of regenerating chains correlate with the duration of the initial phase. A further difference was the amount of brightener adsorbed at the time of change from the first to second phase. This will probably reflect chain length and possibly thickness and composition of the newly formed wall. However, a full understanding of these differences must await further elucidation of the regeneration process, the cause of chain formation and its ultimate reversion to the normal hyphal form.

The method described gives no indication of the proportion of protoplasts that regenerate, but a measure of the rate of formation of new wall by them. However, the fairly equal rates of adsorption during the first phase suggests that similar numbers were regenerating.

J. F. P. thanks the S.R.C. for a grant to support this work. We thank Mr Brian Case for assistance with photographic work and Mr R. K. Gibson for helpful discussion.

\section{REFERENCES}

Bachmann, B. J. \& Bonner, D. M. (1959). Protoplasts from Neurospora crassa. Journal of Bacteriology 78, $550-556$.

Bailey, N. T. J. (1959). Statistical Methods in Biology. London: English Universities Press.

BulL, A. T. (1970). Inhibition of polysaccharases by melanin. Enzyme inhibition in relation to mycolysis. Archives of Biochemistry and Biophysics 137, 345-356.

DARKen, M. A. (1962). Absorption and transport of fluorescent brighteners by micro-organisms. Applied Microbiology 10, 387-393.

Elorza, M. V., Arst, J. R. H. H., Cove, D. J. \& Scazzocchio, C. (I969). Permeability properties of Aspergillus nidulans protoplasts. Journal of Bacteriology 99, I I 3-I 15.

Emerson, S. \& Emerson, M. R. (I958). Production and reversion of protoplast-like structures in the osmotic strain of Neurospora crassa. Proceedings of the National Academy of Sciences of the United States of America 44, 668-67I.

Garciá-Acha, I., López-Belmonte, F. \& Villanueva, J. R. (1966). Regeneration of mycelial protoplasts of Fusarium culmorum. Journal of General Microbiology 45, 515-523.

Gull, K., Moore, P. M. \& Trinci, A. P. J. (1972). Formation of protoplasts from Geotrichum lactis and use of the fluorescence to detect cell walls. Transactions of the British Mycological Society 59, 79-85.

HARrington, B. J. \& Roper, K. B. (1968). Use of a fluorescent brightener to demonstrate cellulose in the cellular slime molds. Applied Microbiology 16, I06-I I3.

Kuster, E. \& Williams, S. T. (1964). Selection of media for the isolation of Streptomyces. Nature, London 202, 928-929.

MAEDA, H. \& ISHIDA, N. (I967). Specificity of binding of hexopyranosyl polysaccharides with fluorescent brightener. Journal of Biochemistry 62, 276-278. 
Nagata, T. \& TAKeBE, I. (1970). Cell wall regeneration and cell division in isolated tobacco mesophyll protoplasts. Planta $92,30 \mathrm{I}-308$.

Paton, A. M. \& Jones, S. M. (I97I). Techniques involving optical brightening agents. In Methods in Microbiology, vol. 5A, pp. I35-144. Edited by J. R. Norris and D. W. Ribbons. London and New York: Academic Press.

Peberdy, J. F. (1971). Protoplasts from Mortierella vinacea. Transactions of the British Mycological Society $56,67-72$.

Peberdy, J. F. \& Gibson, R. K. (197I). Regeneration of Aspergillus nidulans protoplasts. Journal of General Microbiology 69, 325-330.

Preece, T. F. (I97I). Fluorescent techniques in mycology. In Methods in Microbiology, vol. 4, pp. 509-516. Edited by C. Booth. London and New York: Academic Press. 